\title{
Solar activity forcing of terrestrial hydrological phenomena
}

\author{
Pablo J. D. Mauas ${ }^{1}$, Andrea P. Buccino ${ }^{1}$ and Eduardo Flamenco ${ }^{2}$ \\ ${ }^{1}$ Instituto de Astronomía y Física del Espacio, \\ Universidad de Buenos Aires, CONICET \\ C.C. 67 Suc. $28-1428$ \\ Buenos Aires, Argentina \\ email: pablo@iafe.uba.ar, abuccino@iafe.uba.ar \\ ${ }^{2}$ Instituto Nacional de Tecnología Agropecuaria, \\ Rivadavia 1439, 1033, \\ Buenos Aires, Argentina
}

\begin{abstract}
Recently, the study of the influence of solar activity on the Earth's climate received strong attention, mainly due to the possibility, proposed by several authors, that global warming is not anthropogenic, but is due to an increase in solar activity. Although this possibility has been ruled out, there are strong evidences that solar variability has an influence on Earth's climate, in regional scales.

Here we review some of these evidences, focusing in a particular aspect of climate: atmospheric moisture and related quantities like precipitation. In particular, we studied the influence of activity on South American precipitations during centuries. First, we analyzed the stream flow of the Paraná and other rivers of the region, and found a very strong correlation with Sunspot Number in decadal time scales. We found a similar correlation between Sunspot Number and tree-ring chronologies, which allows us to extend our study to cover the last two centuries.
\end{abstract}

Keywords. Solar activity, climate

\section{Introduction}

In the last decades, several authors proposed that global warming is not anthropogenic, but is due instead to an increase in solar activity, a proposition which resulted in a strong interest to study the influence of solar activity on the Earth's climate. This discussion was, of course, of great political interest, and had a strong repercussion in the media. For example, on December 4, 1997, on the Wall Street Journal appeared an article on the subject entitled "Science Has Spoken: Global Warming Is a Myth" (see Fig. 1). This article, together with a copy of a scientific-looking paper (of which there are three versions, e.g. Soon et al. 1999), was massively sent to North American scientists, accompanied by a petition to be presented to the Congress of the Unites States opposing the ratification of the Kyoto protocol.

This article was based on the results obtained by Friis-Christensen and Lassen (1991) and Lassen and Friis-Christensen (1995), who found a similarity between the length of the solar cycle (LCS), smoothed with a 1-2-2-2-1 filter, and the 11-yr running mean of the Northern Hemisphere temperature anomalies. However, this studies were seriously objected by Laut and Gunderman (2000) and Laut (2003). In particular, these results were obtained using the actual, non-smoothed, LSCs for the last 4 cycles. Using the right values, already available 10 years later, it can be seen that the solar cycles had 


\section{WHAT WARMS THE EARTH?}

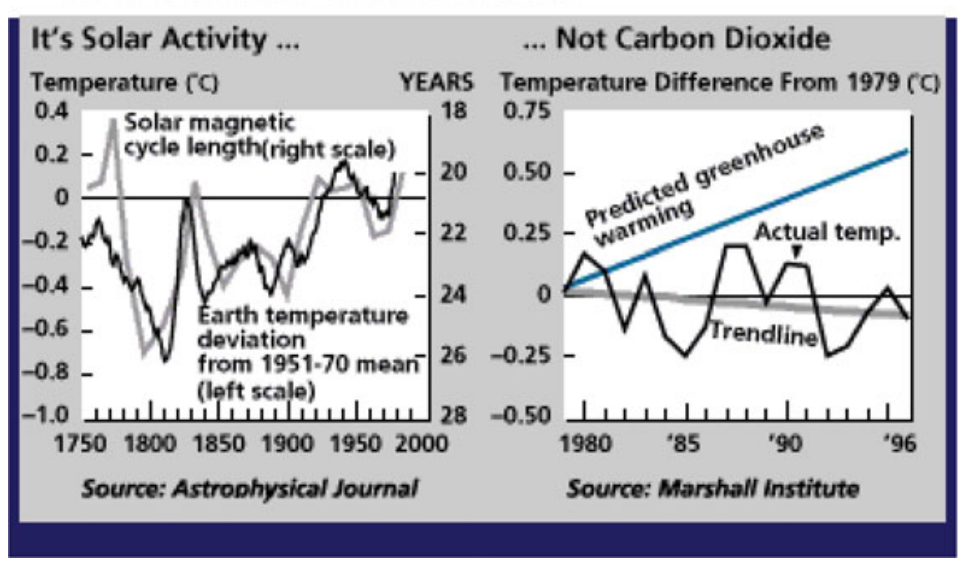

Figure 1. Article on the Wall Street Journal (12/4/1997)

approximately the same length than in the 1970s, while the temperature continued to increase (e.g. see Damon and Peristykh 2005).

Several years later, Friis-Christensen and Svensmark (1997) and Svensmark (1998) found that total cloud cover changed in phase with the flux of galactic cosmic rays (GCR), which are modulated by the interplanetary magnetic field associated with the solar wind and, therefore, with solar activity. They proposed a mechanism for the influence of solar activity on climate, in which GCR would affect cloud formation on Earth, through ionization of the atmosphere. Therefore, during periods of higher solar activity, when the interplanetary magnetic field is larger, and therefore less GCR hit the Earth, the cloud cover would be smaller.

Later on the observed agreement was lost, although Marsh and Svensmark (2000) proposed that it was still visible with low clouds. This theory was criticized by different reasons (e.g. Laut 2003), in particular because GCR should affect more strongly high clouds than low ones. Furthermore, Udelhofen and Cess (2001) studied observations from the ground obtained at 90 meteorological stations in the US during more than 90 years, and found the opposite correlation. At present, the correlation found by Svensmark and collaborators cannot be seen in the data. In fact, Lockwood and Fröhlich (2007) found that all possible solar forcings of climate had trends opposite to those needed to account for the rise in temperatures measured in the last century.

Moreover, the idea that the Sun has played a significant role in modern climate warming was mainly based on a general consensus that solar activity has been increasing during the last 300 years, after the Maunder Minimum, with a maximum in the late 20th century, which some researchers called the Modern Grand Maximum. However, this increase in solar activity has been identified as an error in the calibration of the Group Sunspot Number. When this error is corrected, solar activity appears to have been relatively stable since the end of the Maunder Minimum (see e.g. Svalgaard 2012, and the official IAU release $\dagger$ ).

However, even if global warming cannot be attributed to an increase in solar activity, there is strong evidence that activity can influence terrestrial climate, in local scales. 
In what follows we will review some of that evidence, in particular the one referred to hydrological phenomena, and review our recent work on the subject.

\section{Solar activity and hydrological phenomena}

Usually, studies focusing on the influence of solar activity on climate have concentrated on Northern Hemisphere temperature or sea surface temperature. However, climate is a very complex system, involving many other important variables. Recently, several studies have focused in a different aspect of climate: atmospheric moisture and related quantities like, for example, precipitation.

Perhaps the most studied case is the Asian monsoon, where correlations between precipitations and solar activity have been found in several time scales. For example, Neff et al. (2001) studied the monsoon in Oman between 9 and 6 kyr ago, and found strong coherence with solar variability. Agnihotri et al. (2002) found that the monsoon intensity in India followed the variations of the solar irradiance on centennial time scales during the last millennium. Fleitmann et al. (2003) studied the Indian monsoon during the Holocene, and found that intervals of weak solar activity correlate with periods of low monsoon precipitation, and viceversa. On shorter time scales, Mehta and Lau (1997), found that, at multidecadal time scales, when solar irradiance is above normal there is a stronger correlation between the El Niño 3 index and the monsoon rainfall, and viceversa. Bhattacharyya and Narasimha (2005) and Kodera (2004), among others, also found correlations between solar activity and Indian monsoon in decadal time scales.

The monsoon in southern China over the past 9000 years was studied by Wang et al. (2005) who found that higher solar irradiance corresponds to stronger monsoon. They proposed that the monsoon responds almost immediately to the solar forcing by rapid atmospheric responses to solar changes.

Tiwari and Rajesh (2014) studied groundwater recharge rates in the Chinese region of Mongolia. Groundwater recharge is the hydrologic process where water moves downward from surface water to an aquifer. They found a strong stationary power at 200-220 years, significant at more than $95 \%$ confidence level, with wet periods coincident with strong solar activity periods.

All these studies found a positive correlation, with periods of higher solar activity corresponding to periods of larger precipitation. In contrast, Hong et al. (2001) studied a 6000-year record of precipitation and drought in northeastern China, and found that most of the dry periods agree with stronger solar activity and viceversa. In the American continent, droughts in the Yucatan Peninsula have been associated with periods of strong solar activity and have even been proposed to cause the decline of the Mayan civilization (Hodell et al. 2001).

In the same sense, studies of the water level of the East African Lakes Naivasha (Verschuren et al. 2000) and Victoria (Stager et al. 2005), found that severe droughts were coincident with phases of high solar activity and that rains increased during periods of low solar irradiation. To explain these differences it has been proposed that in equatorial regions enhanced solar irradiation causes more evaporation increasing the net transport of moisture flux to the Indian region via monsoon winds (Agnihotri et al. 2002).

However, these relationships seem to have changed sign around 200 years ago, when strong droughts took place over much of tropical Africa during the Dalton minimum, around 1800-1820 (Stager et al. 2005). Furthermore, recent water levels in Lake Victoria were studied by Stager et al. (2007), who found that during the 20th century, maxima of the $\sim 11$-year sunspot cycle were coincident with water level peaks caused by positive rainfall anomalies $\sim 1$ years before solar maxima. These same patterns were also observed 


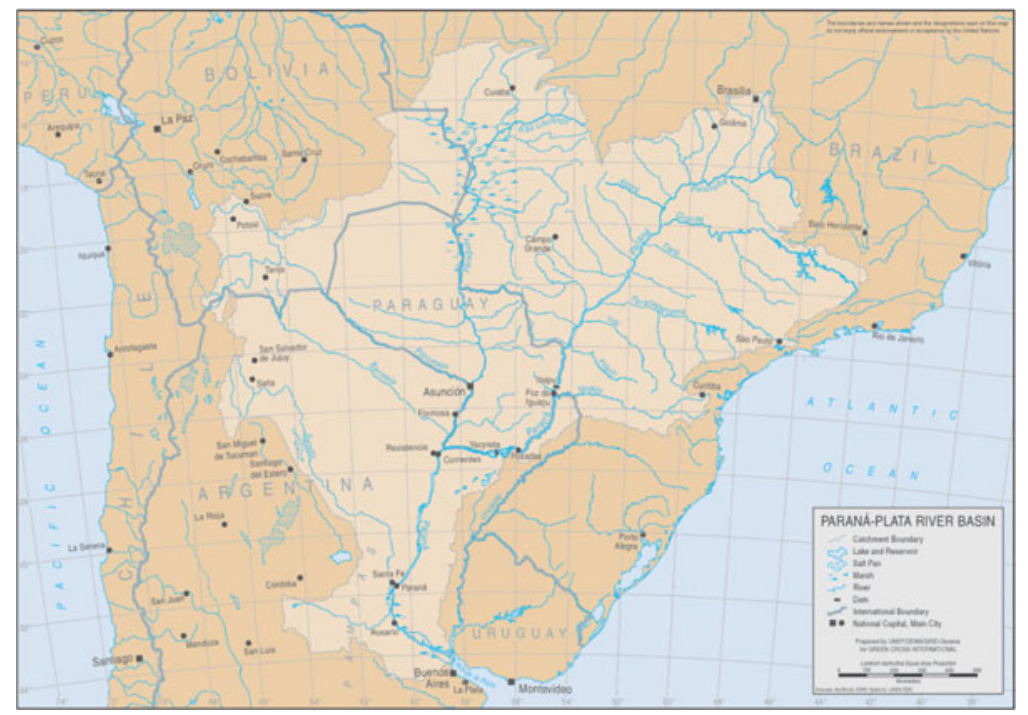

Figure 2. The Paraná basin

in at least five other East African lakes, hinting that these relationships between sunspot number and rainfall were regional in scale.

In Mauas and Flamenco (2005) we took a different approach, and we proposed to use the stream flow of a large river, the Paraná in southern South America, to study precipitations in a large area (see below). In this direction, Ruzmaikin et al. (2006) found signals of solar activity in the river Nile using spectral analysis techniques. They reported an 88-year variation present both in solar variability and in the Nile data. Zanchettin et al. (2008) studied the stream flow of the Po river, and found a correlation with variations in solar activity, on decadal time scales.

\section{Stream flow of the Paraná River}

River stream flows are excellent climatic indicators, and those with continental scale basins smooth out local variations, and can be particularly useful to study global forcing mechanisms. In particular, the Paraná River originates in the southernmost part of the Amazon forest, and it flows south collecting water from the countries of Brazil, Paraguay, Bolivia, Uruguay, and Argentina (see Fig. 2). It has a basin area of over $3.100 .000 \mathrm{~km}^{2}$ and a mean stream flow of $20.600 \mathrm{~m}^{3} / \mathrm{s}$, which makes it the fifth river of the world according to drainage area and the fourth according to stream flow.

Understanding the different factors that have an impact on the flow of these rivers it is fundamental for different social and economic reasons, from planning of agricultural or hydroenergetic conditions to the prediction of floods and droughts. In particular, floods of the Paraná can occupy very large areas, as can be seen in Fig. 3. During the last flood, in 1997, $180000 \mathrm{~km}^{2}$ of land were covered with water, 125000 people had to be evacuated, and 25 people died. Together, the three largest floods of the Paraná during the 20th century caused economic losses of five billion dollars.

In Mauas et al. (2008) we studied the stream flow data measured at a gauging station located in the city of Corrientes, $900 \mathrm{~km}$ north of the outlet of the Paraná. It is measured continuously from 1904, on a daily basis. The yearly data are shown in Fig. 4 together with the yearly sunspot number (SN), which we use as a solar-activity indicator. Also 

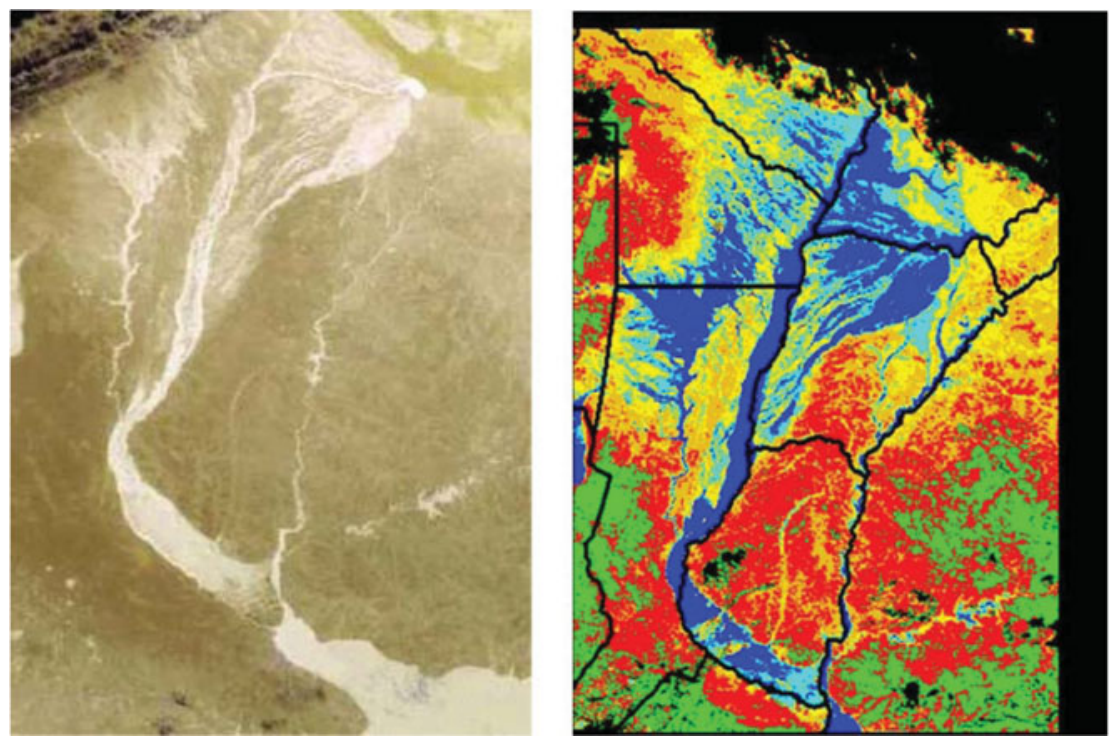

Figure 3. Left: Image taken with the AVHRR instrument on board a NOAA satellite, showing an area of $1200 \mathrm{~km}$ x $500 \mathrm{~km}$, during the flood of the Paraná of 1997-1998. Right: An image in false colors, with political divisions over-imposed. The main area is Argentina. To the East, Uruguay and Brazil. To the North, Paraguay.
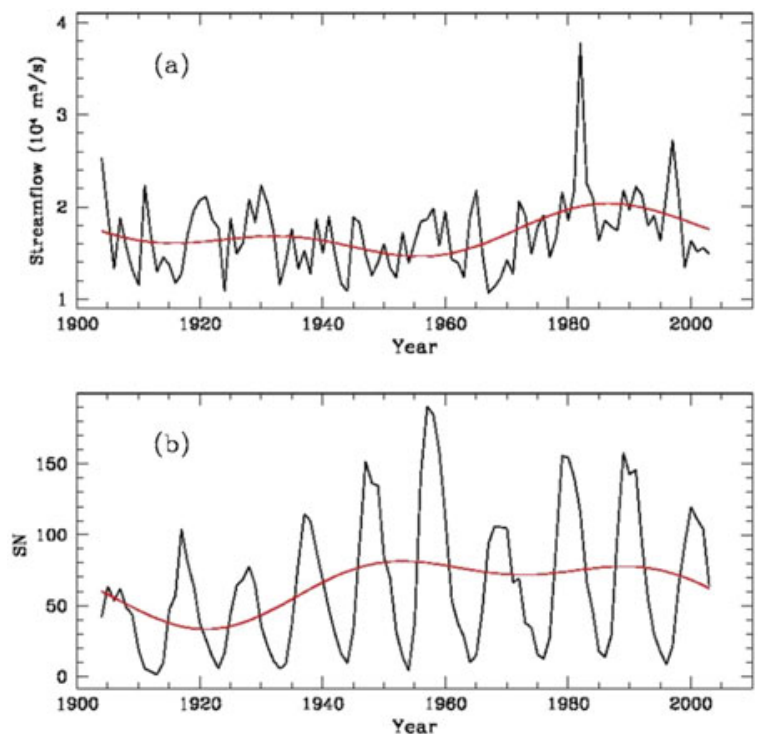

Figure 4. a) Paraná's annual stream flow at the Corrientes gauging station. (b) Yearly international sunspot number (SN). The secular trends, obtained with a low-pass Fourier filter with a 50-yr cutoff, are shown as thick lines.

shown in the figure are the trends, obtained with a low-pass Fourier filter with a 50 years cutoff.

In Fig. 5 we show the stream flow and the SN together. In both cases we have subtracted the secular trend shown in Fig. 4 from the annual data, and we have performed an $11 \mathrm{yr}$ running-mean to smooth out the solar cycle. We have also normalized both quantities by subtracting the mean and dividing by the standard deviation of each series. These lasts 


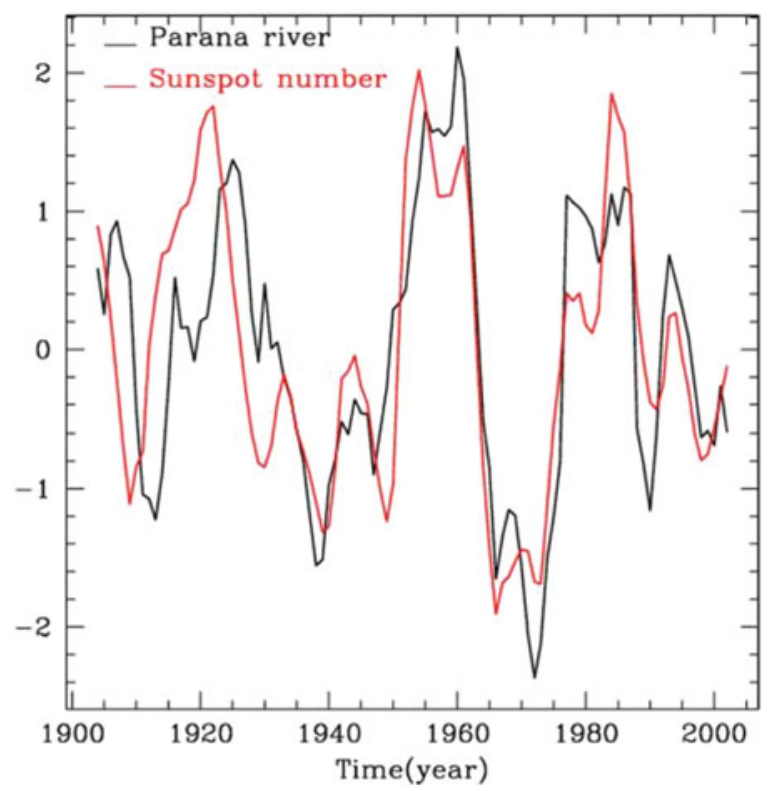

Figure 5. The detrended time series for the Paraná's stream flow and the Sunspot Number. The detrended series were obtained by subtracting from each data series the corresponding secular trend and were smoothed by an 11-yr-running mean to eliminate the solar cycle. Both series were standardized by subtracting the mean and dividing by the standard deviation, to avoid introducing arbitrary free parameters. The Pearsons correlation coefficient is $\mathrm{R}=0.78$.

steps have been done to avoid introducing two free parameters, the relative scales and the offset between both quantities.

It can be seen that there is a remarkable visual agreement between the Paraná's stream flow and the sunspot number. In fact, the Pearson's correlation coefficient is $r=0.78$, with a significance level, obtained through a t-student test, higher than $99.99 \%$. It can also be noted that in this area wetter conditions coincide with periods of higher solar activity.

A few years later, in Mauas et al. (2011) we found that the correlation still held when more years of data were added. In particular, between 1995 and 2003 the Paraná's stream flow and the mean Sunspot Number have both decreased by similar proportions. This is of particular interest, since Solar Cycle 23 was the weakest since the 1970s: SN for the years 2008 (2.9) and 2009 (3.1) have been the lowest since 1913, and the beginning of Solar Cycle 24 was delayed by a minimum with the largest number of spotless days since the 1910s. At the same time, the mean levels of the Paraná discharge were also the lowest since the 1970s (see Fig. 5).

\section{Other South-American Rivers}

In Mauas et al. (2011) we followed up on the study of the influence of solar activity on the flow of South American rivers. In that paper we studied the stream flow of the Colorado river, and two of its tributaries, the San Juan and the Atuel rivers. We also analyzed snow levels, measured near the sources of the Colorado (see Fig. 6).

The Colorado river marks the north boundary of the Argentine Patagonia, separating it from the Pampas, to the northeast, and the Andean region of Cuyo, to the Northwest. Its origin is on the eastern slopes of the Andes Mountains, from where it flows southeast 


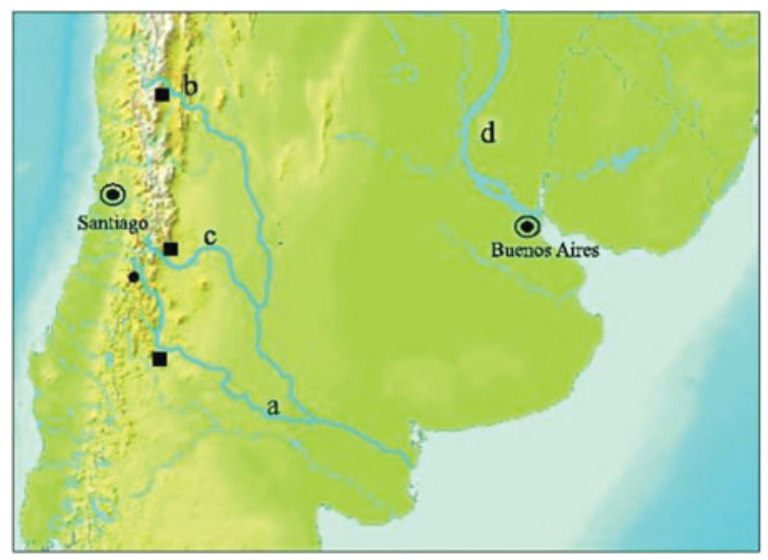

Figure 6. Colorado hydrologic system. The rivers we studied are a. Colorado, b. San Juan, c. Atuel and d. the lower part of the Paraná river. The stream flow (squares) and snow (dot) measuring stations are also indicated.
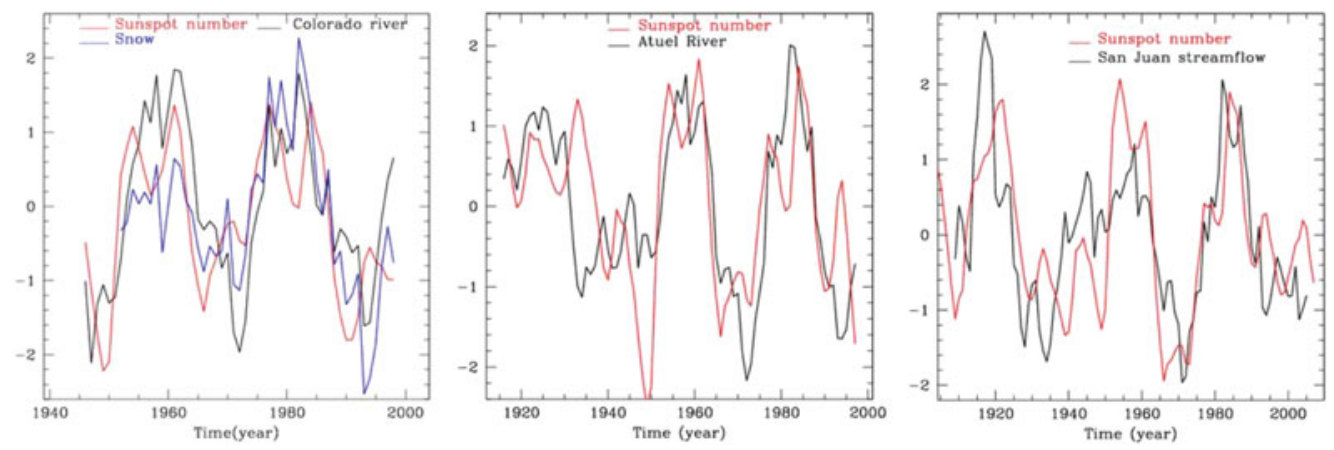

Figure 7. The detrended and renormalized stream flows compared with Sunspot Number. In the left panel the snow level is also shown.

until it discharges in the Atlantic Ocean. The Atuel, which originates in the glacial Atuel Lake, at $3250 \mathrm{~m}$ above sea level in the Andes range, and the $500 \mathrm{~km}$ long San Juan river, join the Colorado downstream of its gauging station. Therefore, the data given by the three series are not directly related.

Unlike the Paraná, whose stream flow is directly related to precipitation, the regime of all these rivers is dominated by snow melting, and their stream flows reflect precipitation accumulated during the winter, and melted during spring and summer. To directly study the snow precipitation, we complete our data with measurements of the height of snow accumulated in the Andes at $2250 \mathrm{~m}$ above Sea level, close to the origin of the Colorado (see Fig. 6), which were measured in situ at the end of the winter since 1952. In fact, the correlation between the stream flow of the Colorado and the snow height is very good, with a correlation coefficient $r=0.87$, significant to a $99 \%$ level.

In Fig. 7 we compare the multidecadal component of the stream flows with the corresponding series for the sunspot number. In all cases we proceed as with the data in Fig. 4: we smoothed out the solar cycle with an 11-year running mean, we detrended the series by subtracting the long term component, and we standardized the data by 


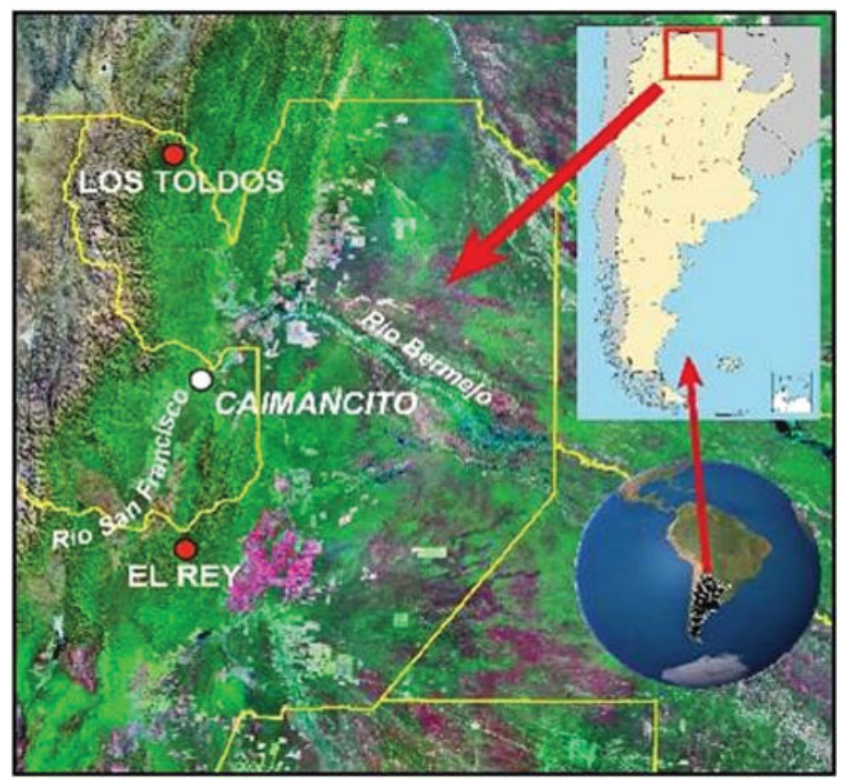

Figure 8. NorthWestern Argentina. Marked in red are the locations from where we obtained the tree-ring chronologies. Image acquired by the LANDSAT satellite.

subtracting the mean and dividing by the standard deviation. In the panel corresponding to the Colorado, we also include the snow height.

It can be seen that in all cases the agreement is remarkable. The correlation coefficients are $0.59,0.47,0.67$ and 0.69 for the Colorado, the snow level, the San Juan and the Atuel, respectively, all significant to the $96-97 \%$ level. Although all these rivers have maximum stream flow during Summer, there is a big difference, however, between the regimes of the Paraná and the remaining rivers: for these ones, the important factor is the intensity of the precipitation occurring as snow during the winter months, from June to August. For the Paraná, what is most important is the level of the precipitation during the summer months. It should also be noticed that, here again, stronger activity coincides with larger precipitation.

\section{Tree rings}

Tree rings are the most numerous and widely distributed high-resolution climate archives in South America. During the last decades, variations of temperature, stream flow, rainfall and snow were reconstructed using tree-ring chronologies from subtropical and temperate forests, which are based on ring width, density and stable isotopes (see Boninsegna et al. 2009 and references therein).

Villalba et al. (1992) studied the spatial patterns of climate and tree-growth anomalies in the forests of northwestern Argentina. The tree-ring data set consisted of seven chronologies developed from Juglans and Cedrela (see Fig. 8). They show that tree-ring widths in subtropical Argentina are affected by weather conditions from late winter to early summer. Tree-ring patterns mainly reflect the direct effects of the principal types of rainfall-patterns observed. One of these patterns is related to precipitation anomalies concentrated in the northeastern part of the region.

To extend back in time and to a larger geographical area the results obtained previously, we study the relation between the Sunspot Number and the tree-ring chronologies studied 


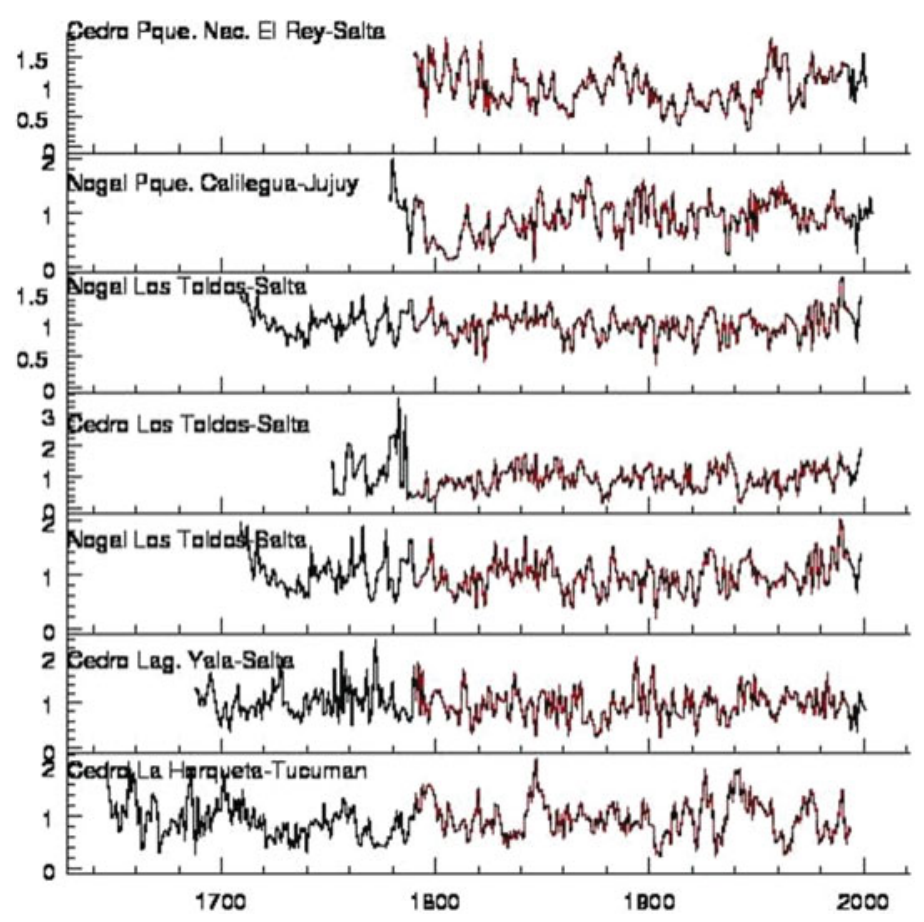

Figure 9. Tree-rings chronologies from Cedrela and Junglans from NorthWestern Argentina. Marked in red are the data used in this work.

by Villalba et al. (1992). These data-sets are shown in Fig. 9. It can be seen that the shortest series starts in 1797, while the longest one goes back to the XVI century. Here we study only the data from 1797 , where all the series overlap.

The individual sets respond to local conditions, in the particular location of the studied tree. To obtain an indication of global conditions in the region, we built an index in the following way. First, we shifted in time each tree-ring series to obtain the best correlation with the Paraná's stream flow. In particular, in 1982 and 1997 there were two very large annual discharges of the Paraná that are associated with two exceptional El Niño events (see Fig. 4). These two events, although weaker, can be seen in the individual tree-ring series, with a small delay, different in each case. We therefore built a composite series as the average between each individual chronology, shifted to match the Paraná's discharge. Finally, we took the 11-years running-mean, and normalized the series as in the previous cases.

The resulting index is shown in Fig. 10, together with the Sunspot Number. It can be seen that also here the agreement is quite good. The Pearson's correlation coefficient between both series is $\mathrm{R}=0.69$.

\section{Discussion}

Although the theory that Global Warming is caused by an increase in Solar activity has been dismissed, particularly because activity and temperature do not have similar trends anymore, it gave a strong impulse to the studies on the relation between climate and activity. In particular, there is strong evidence that the Sun could have an influence in different climatic variables, in different regions of the globe, and not always in the same sense. In particular, we reviewed different studies which concentrate on different aspects of 


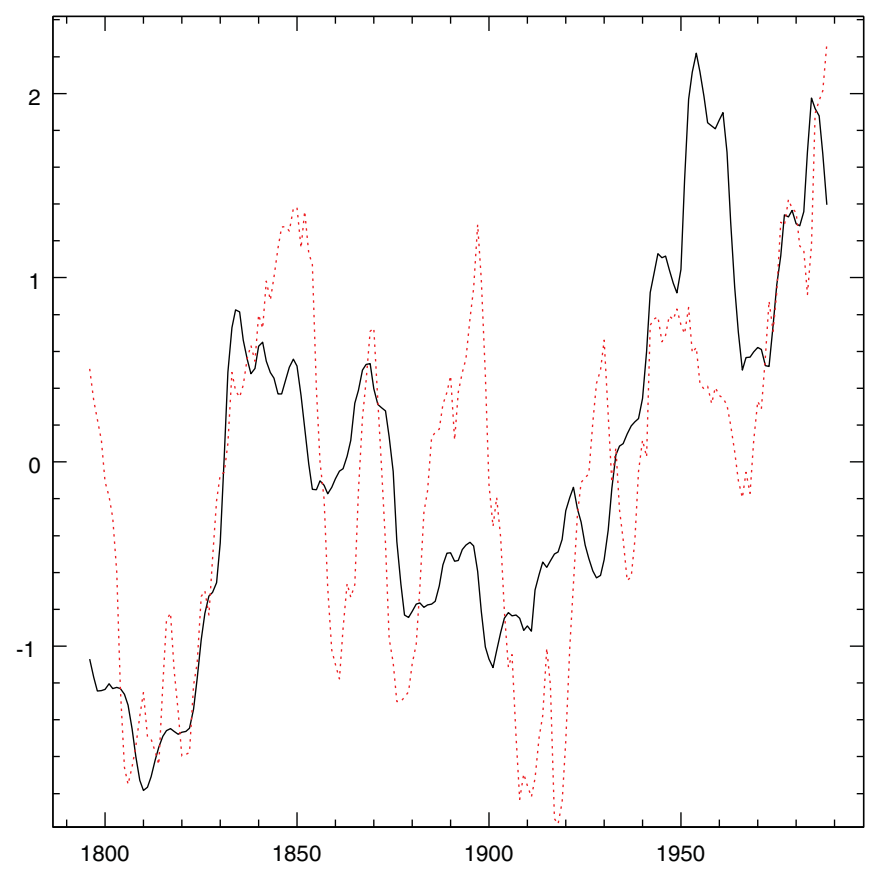

Figure 10. Composite of the tree-rings chronologies (dashed-line) and Sunspot Number (full-line) smoothed by an 11-yr running mean to smooth out the solar cycle. Both series were normalized by subtracting the mean and dividing by the standard deviation. The correlation coefficient is $\mathrm{r}=0.69$.

atmospheric moisture, which in some regions reported positive correlations, with stronger activity related to stronger precipitations, and in others the opposite correlation, with strong droughts coincident with solar activity maxima. There are also regions of the world where this relation changed signs over time.

In particular, we studied different climatic indicators in southern South America. First, we concentrated in the stream flow of one of the largest rivers of the world, the Paraná. We found a strong correlation on decadal time scales between the river's discharge and Sunspot Number. We later found that this correlation was still present during the large solar minimum between Cycles 23 and 24, which corresponded to a period of very low flows in the Paraná.

We can also find in historical records this coincidence between periods with smaller solar activity and low Paraná's discharge. In particular, during the period known as the Little Ice Age there are different reports pointing out to low discharges. For example, a traveler of that period mentions in his diary that in 1752 the level of the river was so small that the small ships of that time could not navigate it. At present, the river can be navigated as far north as Asunción in Paraguay by ships 4 times larger (Iriondo 1999). There other climatic records which point out to reduced precipitations in this region during the Little Ice Age (see Piovano et al. 2009 and references therein). It is well known that the Little Ice Age was coincident with the Maunder Minimum, and was perhaps caused by low solar activity (e.g. Eddy 1976).

To check if the solar influence is also present in other areas of South America, we studied the flow of three other rivers of the region, and the snow level from a mountainhigh station of the same area. Also in this cases we found a strong correlation between the 
Sunspot Number and the stream flows, after removing the secular trends and smoothing out the solar cycle.

Finally, to extended both the area coverage and the temporal baseline, we studied a composite of seven tree-ring chronologies affected by precipitations, starting at the end of the XVIII century. Also in this case we found the same correlation with Sunspot Number.

We point out that, in all cases, we found a correlation in the intermediate time scale. We removed the secular trends when present (e.g, for the Paraná and the Sunspot Number), which are not correlated. We also smoothed out the solar cycle, since on the yearly timescale, the dominant factor influencing precipitations is El Niño. The results we found show that decades of larger precipitations correspond to decades of higher activity, with these variations overimposed on the corresponding secular trends.

In all cases, the correlation we found is positive, i.e., higher precipitations correspond to larger solar activity, in a very large area.

Since another mechanism that has been proposed to explain the Sun-Earth connection involve the modulation of Galactic Cosmic Rays, we also studied the correlation between the Paraná's discharge and two other solar-activity indexes: the neutron count at Climax, Colorado, available since 1953, and the aa index, which is an indication of the disturbance level of the magnetic field of the Earth based on magnetometer observations of two stations in England and Australia, which is available since 1868. Both indexes can be used to test the GCR hypothesis.

We found that the Paraná's stream flow is correlated with both neutron count and the aa index. This was expected, since all activity indexes are correlated among them. However, the correlation with Sunspot Number was strongest, suggesting a direct link between solar irradiance and precipitations.

It has been shown that variations in solar insolation affect the position of the Inter Tropical Convergence Zone (ITCZ) (Poore et al. 2004, Haug et al. 2001). Newton et al. (2006) proposed that a displacement southwards of the ITCZ would enhance precipitations in the tropical regions of southern South America. We found that the increase in precipitations are seen both in the Southern Hemisphere's summer when the ITCZ is over the equator, close to where the Paraná has its origin, and during winter, when the ITCZ moves north, and precipitations increase further South.

\section{References}

Agnihotri, R., K. Dutta, R. Bhushan, \& B. L. K. Somayajulu 2002, Earth and Planetary Science Letters 198, 521.

Berri, G. J., \& E. A. Flamenco 1999. Water Resources Research 35, 3803.

Bhattacharyya, S., \& R. Narasimha 2005. Geophysical Review Letters 32, 5813.

Boninsegna, J. A., Argollo, J., Aravena, J. C. et al., 2009, Palaeogeography, Palaeoclimatology, Palaeoecology 281, 210.

Damon, P. E. \& Peristykh, A. N. 2005, Clim.Change 68, 101

Eddy, J. A. 1976. Science 192, 1189.

Fleitmann, D., S. J. Burns, M. Mudelsee, U. Neff, J. Kramers, A. Mangini, \& A. Matter 2003. Science 300, 1737.

Friis-Christensen E. \& Lassen K. 1991, Science 254, 698700.

Friis-Christensen, E. \& Svensmark, H. 1997, Ad.Spa. Res 20, 913

Haug, G. H., K. A. Hughen, D. M. Sigman, L. C. Peterson, \& U. Röhl 2001. Science 293, 1304.

Hodell, D. A., C. D. Charles, \& F. J. Sierro 2001. Earth and Planetary Science Letters 192, 109.

Hong, Y. T., Z. G. Wang, H. B. Jiang, Q. H. Lin, B. Hong, Y. X. Zhu, Y. Wang, L. S. Xu, X. T. Leng, \& H. D. Li 2001. Earth and Planetary Science Letters 185, 111. 
Iriondo, M. 1999. Quat. Int. 57-58, 112.

Kodera, K. 2004. Geophysical Review Letters 31, 24209.

Lassen K. \& Friis-Christensen E. 1995 JATP 57, 835

Laut, P. 2003, JASTP 65, 801

Laut P. \& Gunderman J. 2000 SOLSPA I, p. 189

Lockwood, M. \& Fröhlich, C., 2007, Proc. R. Soc. A 463, 2447

Marsh, N. D. \& Svensmark, H. 2000, Phys. Rev. Lett. 85, 5004

Mauas, P., \& E. Flamenco 2005. Memorie della Societa Astronomica Italiana 76, 1002.

Mauas, P. J. D.., Flamenco, E., \& Buccino, A. P. 2008, Phys. Rev. Let. 101, 168501

Mauas, P. J. D.., Flamenco, E., \& Buccino, A. P. 2011, JASTP 73, 377

Mehta, V. M. \& K.-M. Lau 1997. Geophysical Review Letters 24, 159.

Neff, U., S. J. Burns, A. Mangini, M. Mudelsee, D. Fleitmann, \& A. Matter 2001. Nature 411, 290.

Newton, A., R. Thunell \& L. Stott 2006. Geophysical Review Letters 33, 19710.

Piovano, E., D. Ariztegui, F. Córdoba, M. Cioccale, \& F. Sylvestre 2009. Past Climate Variability in South America and Surrounding Regions From the Last Glacial Maximum to the Holocene, Chapter 14. Hydrological Variability in South America Below the Tropic of Capricorn (Pampas and Patagonia, Argentina) During the Last 13.0 Ka, pp. 323-351. Springer Netherlands.

Poore, R. Z., T. M. Quinn, \& S. Verardo 2004. Geophysical Review Letters 31, 12214.

Ruzmaikin, A., J. Feynman, \& Y. L. Yung 2006. Journal of Geophysical Research (Atmospheres) 111, 21114.

W. Soon, W. Baliunas, S. L., Robinson, A. B., \& Robinson, Z. W. 1999, Climate Research. 13, 149.

Stager, J. C., A. Ruzmaikin, D. Conway, P. Verburg, \& P. J. Mason 2007. Journal of Geophysical Research (Atmospheres) 112, 15106.

Stager, J. C., D. Ryves, B. Cumming, L. Meeker, \& J. Beer 2005. J. Paleolimnol. 33, 243.

Svalgaard, L, 2012, in Proc. Iau Symp. 286, 27

Svensmark, H. 1998, Phys. Rev. Let. 81, 5027

Udelhofen, P., \& Cess, R. 2001, 28, 2617

Tiwari, R. K. \& Rajesh, R. 2014, Geophys. Res. Lett., 41, 3103

Verschuren, D., K. R. Laird \& B. F. Cumming 2000. Nature 403, 410.

Villalba, R. Holmes, R. L., \& Boninsegna, J. A. 1992, Journal of Biogeography 19, 631

Wang, Y., H. Cheng, R. L. Edwards, Y. He, X. Kong, Z. An, J. Wu, M. J. Kelly, C. A. Dykoski, \& X. Li 2005. Science 308, 854 .

Wang, Y.-M., J. L. Lean, \& N. R. Sheeley, Jr. 2005. ApJ 625, 522.

Zanchettin, D., A. Rubino, P. Traverso, \& M. Tomasino 2008. Journal of Geophysical Research (Atmospheres) 113, 12102. 